Hunt, E. J. F, Wessely, S., Jones, N., et al (2014) The mental health of the UK armed forces: where facts meet fiction. European Journal of Psychotrauma, 5; doi 10.3402; ejpt.v5.23617

Jones, M., Sundin, J., Goodwin, L., et al (2013) What explains posttraumatic stress disorder (PTSD) in UK service personnel? Deployment or something else? Psychological Medicine, 43, 1703-1712
MacManus, D., Dean, K., Jones, M., et al (2013) Violent offending by UK military personnel deployed to Iraq and Afghanistan: a data linkage cohort study. Lancet, 381, 907-917.

Thomas, J. L., Wilk, J. E., Riviere, L. A., et al (2010) Prevalence of mental health problems and functional impairment among active component and national guard soldiers 3 and 12 months following combat in Iraq. Archives of General Psychiatry, 67, 614-623.

\section{THEMATIC PAPER}

\title{
THE MENTAL HEALTH OF MILITARY VETERANS
}

\section{Veteran and military mental health: the Australian experience}

\author{
David Forbes ${ }^{1}$ PhD and Olivia Metcalf ${ }^{2}$ PhD
}

'Professor and Director Australian Centre for Posttraumatic Mental Health, Department of Psychiatry, University of Melbourne, Australia,emaildforbes@ unimelb.edu.au

${ }^{2}$ Research Fellow, Australian Centre for Posttraumatic Mental Health, Department of Psychiatry, University of Melbourne, Australia

Acknowledgements and declaration of conflict of interest: The research centre affiliated with the authors receives funding from the Department of Veterans' Affairs and the Department of Defence

\begin{abstract}
Australia has deployed over 25000 personnel to recent conflicts in the Middle East and has been involved in peacekeeping missions. Australian veterans report elevated rates of mental health problems such as post-traumatic stress disorder, anxiety disorders, affective disorders and substance use disorders. Veteran healthcare is delivered through publicly funded services, as well as through private services, at primary, secondary and tertiary levels. Some of the challenges involve coordination of services for veterans transitioning from Defence to Veterans' Affairs, service delivery across a large continent and stigma inhibiting serviceseeking. Initiatives have been introduced in screening and delivery of evidence-based treatments. While challenges remain, Australia has come a long way towards an integrated and comprehensive approach to veteran mental healthcare.
\end{abstract}

Australia has a long tradition of celebrating its military history, dating back to the Gallipoli campaign in the First World War, which took place shortly after federation. Despite the lack of military success in Gallipoli, the courage and mateship displayed by the Australian soldiers have become stuff of national legend (Stanley, 2002). Although a century has passed, this legend pervades modern Australian culture and is still, for many, synonymous with what it means 'to be an Australian'. As a result of this core identification with military conflicts, the Australian community advocates strongly for the support and care of their veterans, colloquially known as 'diggers'.

Since federation, Australian military personnel have served in both World Wars as well as in other major international conflicts, such as Korea, Vietnam and the Gulf. Australia has deployed over 25000 personnel to recent conflicts in the Middle East, where it maintains a presence. In addition to combat roles, Australia has become a major player in international peacekeeping missions, including spearheading the United Nations mission in East
Timor, as well as humanitarian deployments both in Australia and overseas. This diversity of deployments means that 'contemporary veterans' (defined as having served since 1999) are likely to have participated in a combination of combat, peacekeeping and other deployments. They are also the largest cohort of Australian veterans, at an estimated 61900 in 2013 and rising (Department of Veterans' Affairs, 2013a). In comparison, in 2013 surviving veterans of the Vietnam War and the Second World War numbered 46000 and 58200 , respectively.

\section{Mental health in Australian military and veteran populations}

Several studies have investigated the mental health of Australian veterans, with most reporting substantial morbidity. Comprehensive studies of Australian Korean War veterans (Ikin et al, 2009), Vietnam veterans (O'Toole et al, 2009) and veterans from the first Gulf War (Ikin et al, 2004) have found significantly elevated rates of mental health problems such as post-traumatic stress disorder (PTSD), anxiety disorders, affective disorders and substance use disorders relative to non-deployed personnel and comparable civilian populations. This increased risk of mental health disorders is not restricted to combat deployments. A recently completed study of 1067 Australian Defence Force personnel deployed on one or more peacekeeping missions between 1991 and 2002, for example, revealed surprisingly high rates of mental disorder (Hawthorne et al, 2014). Prevalence rates for disorders such as PTSD, alcohol misuse, depression and anxiety were not only higher than among civilian comparators but also higher than those found following other Australian deployments.

While rates of mental disorder are higher in Australian veterans than among civilians, this is not the case for currently serving military personnel, among whom the overall rate is similar to that among civilians, although rates differ across disorders (McFarlane et al, 2011). Serving personnel were found to have higher 12-month prevalence rates of depression and PTSD and lower rates of alcohol use disorders than a community sample. 
Surprisingly, there was no clear difference between deployed and non-deployed personnel, although rates were higher in those with greater exposure to potentially traumatic events. Given that overall rates of mental disorder in currently serving personnel are comparable to those in civilians, but veteran rates are significantly higher, it is reasonable to speculate that the transition from military to civilian life is a high-risk period for the development of mental health conditions. Little is known about the mental health status of members who have recently transitioned out of the Defence Force but a large research project (the Mental Health and Wellbeing Transition Study) is currently underway to explore this question.

\section{Mental healthcare for veterans in Australia: strengths and challenges}

While strong community support exists, several challenges confront the delivery of mental health services to Australian veterans. The care of veterans is managed by two federal government departments, the Department of Defence and the Department of Veterans' Affairs (DVA), which function independently and have largely exclusive service systems. This can lead to increased burden and confusion for those applying for assistance, bureaucratic delays and needy individuals slipping through gaps that exist between the service systems. Both departments recognise these limitations and are committed to working together more closely. A memorandum of understanding signed in 2013 proposes a 'support continuum' of care that formally recognises the specific roles each department plays in providing care to veterans and their families (Department of Veterans' Affairs, 2013b). Such collaborations extend to research projects, a good example being the Mental Health and Wellbeing Transition Study mentioned above. Both departments recognise that the transition from military to civilian life is critical and requires a cohesive service and continuity of care.

Veteran healthcare is delivered through a range of publicly funded state and federal health services, as well as through private services at primary, secondary and tertiary levels. Some of the greatest challenges in service delivery are geographical. Australia is a large continent with a small population, featuring sparsely located capital cities around the perimeter of the country and often vast distances separating rural towns. For those living in rural and remote locations, the lack of local healthcare resources, as well as the time and cost of travel to the nearest facilities, are barriers to effective care. Technological developments are able to overcome some of these challenges and many recent mental health initiatives introduced by the Department of Defence and DVA attempt to address these barriers through the use of telemedicine, online resources and mobile app technology.

Another substantial barrier to mental healthcare is stigma, a problem common in varying degrees to all defence forces. The most frequently reported barrier to Australian military personnel seeking help for emotional or mental health problems was concern that it may reduce deployability; in one survey over a quarter of respondents were concerned about being seen as weak (McFarlane et al, 2011). The current Mental Health and Wellbeing Action Plan initiated by the Department of Defence is aimed at tackling stigma by increasing mental health literacy and awareness. Specific programmes such as 'Keep Your Mates Safe' are aimed at building peer support networks by training individuals to recognise signs of psychological distress and provide support to their colleagues. DVA has mounted similar campaigns to tackle stigma and other barriers to mental healthcare (see http://www.defence.gov.au/health and http:// www.at-ease.dva.gov.au for examples of such mental health programmes).

\section{Tackling problems: screening, identification and early intervention}

Both the Department of Defence and DVA recognise the benefits of early identification of mental health problems. The former conducts screening at critical points in the military life cycle, including post-deployment, after serious incidents and during transition to civilian life. While the ability of population screening to identify potential cases accurately remains a matter of debate, the screening programme has the added benefit of raising awareness and providing a context for simple low-level interventions and support. In 2014, DVA announced a new comprehensive health assessment accessible through general practitioners with the aim of identifying and diagnosing mental health problems early.

In addition to screening and identification, a comprehensive approach to mental health requires attention to prevention and intervention. BattleSMART (Self-Management and Resilience Training) for military personnel is targeted at the earliest stage of intervention, focusing on building psychological resilience and coping strategies among serving personnel with a view to preventing the development of mental health problems. Although further research on such interventions is urgently required, preliminary evaluations are encouraging (Cohn et al, 2010). Similarly, international expert consensus promotes psychological first aid (PFA) as the recommended intervention in the immediate aftermath of a potentially traumatic event and this is now routinely employed.

For those with diagnosable psychiatric conditions such as PTSD, depression, anxiety and substance use disorders, free treatment is available to veterans and serving personnel through private and public sector providers, as well as through DVA's own Veterans and Veterans' Families Counselling Service (VVCS). Mental health treatments funded by the Department of Defence or DVA are expected to be evidence based. Although some clinical accountability mechanisms are in place, ensuring that all treatment provided to veterans and serving personnel is high quality and evidence based remains a challenge. A higher level of 
accountability is applied to PTSD treatments, particularly group programmes (Forbes et al, 2008). In line with the 2008 US Veterans Affairs mandate, it is expected that Australian veterans with PTSD have access to prolonged exposure or cognitive processing therapy (CPT). Recent local research demonstrated the efficacy of CPT for Australian veterans (Forbes et al, 2012) and this approach is being systematically rolled out through the VVCS.

\section{Conclusions}

Psychiatric casualties will always be a part of war and it is incumbent on those tasked with the care of veterans to provide the best possible prevention, early intervention, treatment and long-term management. While many challenges remain, Australia has come a long way in the past few decades towards an integrated and comprehensive approach to veteran mental healthcare.

\section{References}

Cohn, A., Hodson, S. \& Crane, M. (2010) Resilience training in the Australian defence force. InPsych: The Bulletin of the Australian Psychological Society Ltd, 32, 16.

Department of Veterans' Affairs (2013a) Annual Report 2012-13. DVA.

Department of Veterans' Affairs (2013b) The relationship between DVA and Defence. At http://www.dva.gov.au/aboutDVA/
publications/corporate/annualreport/2012-13/overview/Pages/ defence.aspx (accessed 18 July 2014).

Forbes, D., Lewis, V., Parslow, R., et al (2008) Naturalistic comparison of models of programmatic interventions for combatrelated post-traumatic stress disorder. Australian and New Zealand Journal of Psychiatry, 42, 1051-1059.

Forbes, D., Lloyd, D., Nixon, R., et al (2012) A multisite randomized controlled effectiveness trial of cognitive processing therapy for military-related posttraumatic stress disorder. Journal of Anxiety Disorders, 26, 442-452

Hawthorne, G., Korn, S. \& Creamer, M. (2014) Australian Peacekeepers: Long-Term Mental Health Status, Health Service Use and Quality of Life. Technical Report, Department of Psychiatry, University of Melbourne.

Ikin, J. F., Sim, M. R., Creamer, M. C., et al (2004) War-related psychological stressors and risk of psychological disorders in Australian veterans of the 1991 Gulf War. British Journal of Psychiatry, 185, 116-126.

Ikin, J. F., Sim, M. R., McKenzie, D. P., et al (2009) Life satisfaction and quality in Korean War veterans five decades after the war. Journal of Epidemiology and Community Health, 63, 359-365.

McFarlane, A. C., Hodson, S. E., Van Hooff, M., et al (2011) Mental Health in the Australian Defence Force: 2010 ADF Mental Health and Wellbeing Study: Full Report. Department of Defence.

O'Toole, B. I., Catts, S. V., Outram, S., et al (2009) The physical and mental health of Australian Vietnam veterans 3 decades after the war and its relation to military service, combat, and post-traumatic stress disorder. American Journal of Epidemiology, 170, 318-330.

Stanley, P. (2002) The Anzac spirit. At http://www.awm.gov.au/ encyclopedia/anzac/spirit (accessed 18 July 2014).
THEMATIC PAPER

\section{THE MENTAL HEALTH OF MILITARY VETERANS}

\section{Out of the shadows: mental health of Canadian armed forces veterans}

\author{
James M. Thompson ${ }^{1}$ MD CCFP(EM) FCFP, Mark A. Zamorski ${ }^{2}$ MD MHSA CCFP, \\ Deniz Fikretoglu ${ }^{3}$ PhD, Linda VanTil ${ }^{4}$ DVM MSc, Jitender Sareen ${ }^{5}$ MD FRCPC(C), \\ Mary Beth MacLean ${ }^{6}$ MA, Pasqualina Carrese ${ }^{7}$ MPs, Stewart Macintosh ${ }^{8}$ BA MA \\ and David Pedlar ${ }^{9} \mathrm{PhD}$
}

${ }^{1}$ Medical Advisor, Research Directorate, Veterans Affairs Directora, Veterans Affairs Canada, Charlottetown, and Adjunct Associate Professor Department of Public Health Sciences, Queen's University, Kingston, Ontario, Canada, email research-recherche@ vac-acc.gc.ca

${ }^{2}$ Senior Medical Epidemiologist, Directorate of Mental Health, Canadian Forces Health Services Group, Ottawa, and Department of Family Medicine, Faculty of Medicine, University of Ottawa, Canada

${ }^{3}$ Defense Scientist, Defence Research and Development Canada, Toronto Research Canada, Toronto
Centre, Canada

${ }^{4}$ Epidemiologist, Research Directorate, Veterans Affairs Canada, Charlottetown, Prince Edward Island, Canada
In the past $\mathbf{1 5}$ years in Canada, as in other nations, the mental health of veterans has emerged as a key concern for both government and the public. As mental health service enhancement unfolded, the need for wider population studies became apparent. This paper describes the renewal of services and key findings from national surveys of serving personnel and veterans.

In the past 15 years in Canada, as in other countries, the mental health of veterans has emerged as a key concern for both government and the public. Policies and programmes tailored for Second World War veterans dominated in Canada until the wake of the difficult deployments in the Persian Gulf, the Balkans, Somalia, Rwanda and elsewhere in the 1990s. A 1999 survey of contemporary
(post-Korean War) serving Canadian armed forces (CAF) personnel and veterans (ex-service CAF personnel) participating in Veterans Affairs Canada (VAC) programmes brought to light the extent of mental health problems. The CAF, Department of National Defence (DND) and VAC recognised the need to strengthen mental health services for serving personnel and veterans.

This emerging awareness of mental health issues in military populations and increased recognition of post-traumatic stress disorder (PTSD) coincided with national efforts to bring the mental health of all Canadians out of the shadows. Studies conducted in the 1990s included only serving personnel and veterans who were receiving services from VAC, who today represent less than $12 \%$ of the estimated 599200 contemporary CAF veterans. As mental health service enhancement unfolded, the need for wider population 